\title{
Temperature and genotypic effects on life history and fluctuating asymmetry in a field strain of Culex pipiens
}

\author{
M Mpho, A Callaghan and GJ Holloway \\ Division of Zoology, School of Animal and Microbial Sciences, The University of Reading, Whiteknights PO Box 228, Reading RG6 \\ $6 A J, U K$
}

Fluctuating asymmetry (FA) has been proposed as a tool to measure levels of stress experienced by populations of organisms during development. To be of value as a biomarker to highlight conditions at particular sites, it is important that variation in FA is due to environmental (eg pollution) variation and not genetic variation among populations and families, in other words heritability for FA should be very close to zero. A full-sib design was set up in which families of Culex pipiens mosquitoes collected from the field were reared at three different developmental temperatures. The effects of temperature and family on developmental rate, egg to adult survival and four wing morphological measures were assessed. There was both a temperature and a family effect on development rate and survival. Temperature affected all four wing traits, but an influence of family was only evident in two of the wing traits. Two separate measures of FA for each of the wing traits were obtained. The mean estimates of FA were mainly around $1 \%$ of the value of the character measured. There was evidence of an increase in FA with increase in temperature stress. Heritability was estimated for the wing traits and wing trait FA's using restricted estimation maximum likelihood. The estimates of heritability for the wing traits were small and, individually, did not differ significantly from zero. There was also no evidence of heritable genetic variation for any of the wing trait FA's. The results are discussed in relation to other studies where FA heritabilities have been estimated and in relation to the use of $\mathrm{FA}$ as an indicator of environmental stress.

Heredity (2002) 88, 307-312. DOI: 10.1038/sj/hdy/6800045

Keywords: Culex pipiens; heritability; wing morphology; fluctuating asymmetry; environmental stress

\section{Introduction}

Fluctuating asymmetry (FA) has been proposed as a tool to measure the developmental stability of organisms (Zakharov, 1992). The basis of the importance of this measure is the assumption that both sides of a character are under the control of the same genes and that any deviation from the normal bilaterally symmetrical phenotype would be due to perturbation of environmental or genetic origin during ontogeny. A number of studies have found an association between increasing FA and environmental or genetic stress (reviewed in Allendorf and Leary, 1986; Palmer and Strobeck, 1986). Although many studies support this, some failed to find any association between FA and environmental stress (eg Rabitsch, 1997; Dobrin and Corkum, 1999; Bjorksten et al, 2000; Mpho et al, 2000) or genetic stress (Møller, 1992; Fowler and Whitlock, 1994; Sheridan and Pomiankowski, 1997; Hunt and Simmons, 1997; Woods et al, 1998; Floate and Fox, 2000). The disproportional representation of positive to negative association in the literature could be because many negative results are not reported.

FA has been reported to be negatively correlated with fitness in a wide range of organisms (Møller, 1996; reviewed in Møller, 1997). This has led to the formulation

Correspondence: GJ Holloway, Division of Zoology, School of Animal and Microbial Sciences, The University of Reading, Whiteknights PO Box 228, Reading RG6 6AJ, UK. E-mail: g.j.holloway@reading.ac.uk

Received 11 June 2001; accepted 10 November 2001 of the hypothesis that FA may provide a direct measure of genetic quality, with genetically superior individuals being more symmetric than individuals of lower genetic quality (Møller and Pomiankowski, 1994). However, the relationship between FA and fitness is not always consistent (Markow and Ricker, 1992; Ueno, 1994), with some studies reporting a negative relationship (eg Thornhill and Sauer, 1992; Møller and Thornhill, 1997; Møller and Zamora-Munoz, 1997) whereas others did not (Hunt and Simmons, 1997, 1998; Goulson et al, 1999; Tomkins and Simmons, 1999; Bjorksten et al, 2000).

The genetic quality hypothesis assumes that FA has a heritable genetic component. The existence of significant levels of genetic variation for FA is the most contentious area of developmental stability studies. Møller and Thornhill (1997) recently reported significant mean heritability of FA. This was met with scepticism and disputes on grounds that many of the studies on heritable variation were flawed (Leamy, 1997; Markow and Clarke, 1997; Whitlock and Fowler, 1997) and that the analyses used were inappropriate (Leamy, 1997; Markow and Clarke, 1997). Although some studies have detected significant heritable variation for FA (eg Thornhill and Sauer, 1992) many more have reported low and non-significant heritability estimates of FA (Hunt and Simmons, 1997, 1998; Tomkins and Simmons, 1998; Woods et al, 1998; Windig, 1998; Leamy, 1999; Van Dongen et al, 1999; Bjorksten et al, 2000). Due to these inconsistencies, clearly more research work still needs to be done. For FA to be of any evolutionary significance, it must be a reflection 
of genetic quality and must display heritable genetic variation (Goulson et al, 1999).

This study investigates the effect of rearing temperature on life history and phenotypic variation of wing morphological characters in a British field strain of Culex pipiens mosquitoes, with special reference to the heritability of wing trait size and wing trait FA. The design followed allowed testing for the effect of rearing temperature on level of asymmetry, ie whether FA increases with increase in temperature stress. It also enabled the estimation of genotype (family) performance within and across a range of developmental temperatures. Significant genotype $\times$ environment interaction effects would indicate variation among families attributable to genetic differences. Consistent rank of level of FA among families across environments would indicate that FA is a good measure of genetic quality, whereas a random pattern might be an indication that FA is purely environmentally determined (Bjorksten et al, 2000). The more variation in FA reflects variation in environmental conditions, the greater the potential of FA as a biomarker of environmental quality.

\section{Materials and methods}

\section{Establishment of families}

Culex pipiens lays eggs in boat-like rafts, which permits easy collection of single families. Egg rafts were collected from a garden water butt in Reading (Berkshire, England) in June 1998. To make sure that eggs were laid within $12 \mathrm{~h}$ of each other, egg rafts were removed the night before a morning collection of freshly laid rafts. In the laboratory individual rafts were placed in $1 \mathrm{~L}$ plastic tubs with $500 \mathrm{ml}$ of tap water and reared as a family. Fish food (Trouw, UK) was used as the standard larval diet. The larvae were counted at the second instar larval stage and only those families that had more than 225 progeny were kept for use in the subsequent experiments. Larvae and adults from each family were taken to confirm species identity using a key to British mosquitoes (Cranston et al, 1987).

\section{Experimental design and rearing of families}

A full-sib design was used to test for the effects of rearing temperature on the life history and FA of wing traits. Seven full-sib families were each divided into three and each part raised at a different temperature $\left(25^{\circ} \mathrm{C}, 30^{\circ} \mathrm{C}\right.$ and $37^{\circ} \mathrm{C}$ ) representing different levels of stress. Three replicates of 25 larvae per family were set up and reared to adult stage at each of the respective temperatures in $140 \mathrm{ml}$ water in plastic cups.

\section{Dissection and measurement of wing morphological characters}

The measurement of wing morphological characters using image analysis followed the method detailed in Mpho et al (2000). Four traits were measured: wing length $(W L)$, measured as the linear distance from the distal end of the alula to the peripheral tip of the $R_{3}$ vein; D6, the linear distance from the junction of the radio-medial cross vein and medial vein to the peripheral tip of the $R_{4+5}$ vein; D8, the linear distance from the junction of the radiomedial cross vein and medial vein to the peripheral tip of the $R_{2}$ vein; wing area (WA); the surface area of the wing (excluding the fringe) to the bend of the trailing edge of the alula and joining the subcosta with a perpendicular line. All linear and area measurements were measured to an accuracy of $0.01 \mathrm{~mm}$ and $0.01 \mathrm{~mm}^{2}$, respectively. Each wing character was measured four times, without reference to the previous set of measurements.

\section{Environmental and genotypic effects on life-history,} character size and FA

Environmental and genotypic effects on life-history, character size and FA phenotypes were tested using twoway mixed model analysis of variance, with 'temperature' as a fixed factor and 'family' as a random factor. The analyses were performed separately for each sex. The linear model for the analysis was specified as follows:

$$
\mathrm{Y}_{i j}=\mu+\mathrm{T}_{i}+\mathrm{F}_{j}+\mathrm{TF}_{i j}
$$

where $Y_{i j}$ is the mean phenotype of the trait under consideration, $\mu$ is the population mean, $T_{i}$ is the effect of the $i$ th temperature, $F_{j}$ is the effect due to the $j$ th family and $\mathrm{TF}_{i k}$ is the effect due to the interaction of the temperature and the family.

\section{Effects of temperature on life history parameters}

Development time and survival (measured from egg hatch to adult eclosion) were measured for each family at the three temperatures. Pupae from each replicate were isolated daily and placed in a separate cup and then placed at the respective temperature for adult eclosion. Adults that emerged daily were collected, placed in sample tubes and stored in a $-20^{\circ} \mathrm{C}$ freezer until further analysis.

\section{FA analysis}

The FA analysis followed the method detailed in Mpho et al (2000). Two FA indices were obtained: FA1, the mean absolute difference between the left and the right sides of a character $\left[\left(\Sigma\left|R_{i}-L_{i}\right|\right) / N\right)$ and FA10, the measurement error corrected variances between the sides (Palmer, 1994). A third composite asymmetry index, sumFA, was obtained by summing FA values across three traits $(\mathrm{WL}$, D6 and D8), after standardizing the individual unsigned difference between sides by subtracting the sample mean from each datum (Bennett and Hoffmann, 1998; Leamy, 1999). Standardisation in this manner ensures that all traits contribute equally to the measurement of developmental stability (Bennett and Hoffmann, 1998) and tests for the overall organism-wide effect of the environment (Bjorksten et al, 2000).

\section{Heritability estimation of wing character size and FA}

Heritability of wing trait size and FA was estimated using the 'animal model' restricted estimation maximum likelihood (REML) (Meyer, 1997). An unbiased design was employed due to differential survival among temperature treatments. Individuals were taken from different replicate cups to minimize the effect of common rearing environment. The heritability of each trait was estimated separately for each of the developmental temperatures since a heritability estimate is specific to a given population in a given environment (Falconer, 1989). The nature of the experimental design (full-sib analysis) meant that the heritability estimates in this study could be inflated through maternal, common 
environmental and non-additive gene effects (Falconer, 1989; Roff, 1997). Significance of the $h^{2}$ estimates from zero was tested using a simple z-test.

All data were analysed using Minitab Release 10.51, Genstat (4th edition for Windows) and Palmer's Microsoft Excel spreadsheet based on formulae and analyses in Palmer and Strobeck (1986) and Palmer (1994). The spreadsheet is available at http:// gause.biology.ualberta.ca/palmer.hp/asymmetry.html.

\section{Results}

\section{Effects of temperature on life-history parameters}

Development time, measured as the mean number of days from egg hatch to adult eclosion, was influenced by genotype (family) $\left(\mathrm{F}_{6,42}=85.21, P<0.001\right)$ and rearing temperature $\left(\mathrm{F}_{2,42}=281.17, P<0.001\right)$. The mean development time was shortest at $37^{\circ} \mathrm{C}(14.98 \pm 0.42$ days $)$, intermediate at $30^{\circ} \mathrm{C}(15.86 \pm 0.46$ days $)$ and longest at the temperature of $25^{\circ} \mathrm{C}$ (18.24 \pm 0.42 days). A multiple comparison test (Tukey HSD) revealed that the developmental duration at $25^{\circ} \mathrm{C}$ was significantly longer than the developmental durations at the other two temperatures, but there was no significant difference in developmental duration between $30^{\circ} \mathrm{C}$ and $37^{\circ} \mathrm{C}$. There was no interaction between genotype and rearing environments $\left(F_{12,42}\right.$ $=0.58, P=0.844$ ).

The survival data were transformed into proportions and then normalised for ANOVA by arcsine transformation. Survival was variable among families $\left(\mathrm{F}_{6,42}=10.52\right.$, $P<0.001)$ and across the temperatures $\left(\mathrm{F}_{2,42}=39.39, P\right.$ $<0.001$ ). Survival was highest at $30^{\circ} \mathrm{C}$ (mean proportion of adults surviving in each family: $0.43 \pm 0.039)$, intermediate at $25^{\circ} \mathrm{C}(0.39 \pm 0.033)$ and lowest at $37^{\circ} \mathrm{C}(0.19 \pm$ 0.020). A multiple comparison test of all temperature means showed a significant difference between $37^{\circ} \mathrm{C}$ and the other two temperatures $\left(25^{\circ} \mathrm{C}\right.$ and $\left.30^{\circ} \mathrm{C}\right)$ but no significant difference between $25^{\circ} \mathrm{C}$ and $30^{\circ} \mathrm{C}$. The genotypeenvironment interaction was significant $\left(\mathrm{F}_{12,42}=3.11, P=\right.$ 0.003 ) indicating that family rank varied with temperature. If survivorship is used as a measure of the magnitude of the stress experienced by the organisms, it can be clearly seen that $37^{\circ} \mathrm{C}$ was the most stressful developmental temperature to the mosquitoes.

The effects of rearing temperature on wing morphological characters are presented in Table 1. Analysis of

variance of the morphological characters showed that temperature and sex were the main sources of variation ( $P<0.001$ in both cases). All the morphological characters significantly decreased in size with increase in temperature (Table $1, P<0.001$ in all cases). The family effect was significant for D6 and D8 ( $P<0.01$ in both cases), indicating genetic variability among families for these characters, but not for WL and WA. No significant temperature $\times$ sex interaction was observed for $\mathrm{WL}$, but it was significant for D6, D8 and WA $(P<0.05$ at least in all cases). There was also a significant temperature $\times$ family effect for the characters WL, D6 and D8 $(P<0.05$ at least in all cases) indicating phenotypic plasticity for these characters in relation to developmental temperature.

\section{FA analysis}

Three characters conformed to the conditions required for FA analysis: WL, D6 and D8 (see Palmer, 1994). WA displayed significant directional asymmetry and skewness and was therefore excluded from the FA analysis. Since no significant differences in FA were observed across families, the results were pooled over all the families and then the temperature effect was tested. Table 2 summarises the mean levels of FA found. Mean FA was mainly around $1 \%$ of the value of the mean character value. A significant temperature effect on FA1 was observed in females for the characters WL $\left(\mathrm{F}_{2,247}=6.71\right.$, $P=0.001)$ and D8 $\left(\mathrm{F}_{2,247}=4.20, P=0.016\right)$, but no effect was observed for the character D6 $\left(\mathrm{F}_{2,247}=2.33, P=0.099\right)$ (Table 2). Combining the asymmetry of the individual traits into a composite index, sumFA, did not result in a significant difference across temperatures (Table 2). In males, no significant effect of temperature was detected on any of the character FA values (Table 2).

There was a significant increase in FA10 with increase in temperature with the highest FA10 values recorded at $37^{\circ} \mathrm{C}$ for all the characters in both sexes (Figure 1). All the FA10 values of the three wing morphological characters varied significantly across developmental temperature in females $\left(\mathrm{F}_{\max }, P<0.01\right.$ in all cases), but only one character (D6) varied significantly in males $(P<0.05)$, although FA for the other characters also increased with temperature (Figure 1).

\section{Estimation of heritability of wing traits and FA}

None of the wing trait measures or FA displayed heritabilities deviating significantly from zero at any of the

Table 1 Mean \pm s.e. of wing morphological traits ( $W L=$ wing length, D6 and D8 are linear measurements within the wing (see text for details) all measured in $\mathrm{mm}, \mathrm{WA}=$ wing area measured in $\mathrm{mm}^{2}$ ) of a field population of Culex pipiens mosquitoes reared at different temperatures. $n=$ sample size

\begin{tabular}{|c|c|c|c|c|c|c|c|}
\hline & \multirow[t]{2}{*}{ Trait } & \multicolumn{2}{|c|}{$25^{\circ} \mathrm{C}$} & \multicolumn{2}{|c|}{$30^{\circ} \mathrm{C}$} & \multicolumn{2}{|c|}{$37^{\circ} \mathrm{C}$} \\
\hline & & $n$ & Mean \pm s.e. & $n$ & Mean \pm s.e. & $n$ & Mean \pm s.e. \\
\hline Female & $\begin{array}{l}\text { WL } \\
\text { D6 } \\
\text { D8 } \\
\text { WA }\end{array}$ & $\begin{array}{l}104 \\
104 \\
104 \\
104\end{array}$ & $\begin{array}{l}3.43 \pm 0.028 \\
1.52 \pm 0.014 \\
1.51 \pm 0.015 \\
2.61 \pm 0.042\end{array}$ & $\begin{array}{l}101 \\
101 \\
101 \\
101\end{array}$ & $\begin{array}{l}3.23 \pm 0.020 \\
1.40 \pm 0.009 \\
1.39 \pm 0.010 \\
2.31 \pm 0.029\end{array}$ & $\begin{array}{l}47 \\
47 \\
47 \\
47\end{array}$ & $\begin{array}{l}3.02 \pm 0.028 \\
1.29 \pm 0.015 \\
1.28 \pm 0.016 \\
2.01 \pm 0.037\end{array}$ \\
\hline Male & $\begin{array}{l}\text { WL } \\
\text { D6 } \\
\text { D8 } \\
\text { WA }\end{array}$ & $\begin{array}{l}84 \\
84 \\
84 \\
84\end{array}$ & $\begin{array}{l}2.84 \pm 0.022 \\
1.16 \pm 0.010 \\
1.14 \pm 0.010 \\
1.66 \pm 0.027\end{array}$ & $\begin{array}{l}92 \\
92 \\
92 \\
92\end{array}$ & $\begin{array}{l}2.76 \pm 0.020 \\
1.11 \pm 0.010 \\
1.09 \pm 0.010 \\
1.60 \pm 0.026\end{array}$ & $\begin{array}{l}39 \\
39 \\
39 \\
39\end{array}$ & $\begin{array}{l}2.66 \pm 0.024 \\
1.05 \pm 0.015 \\
1.03 \pm 0.015 \\
1.48 \pm 0.030\end{array}$ \\
\hline
\end{tabular}


Table 2 FA1 of wing morphological traits of female and male adult Culex pipiens reared at different temperatures $(W L=$ wing length; D6 and D8 = measure of distances within the wing measured in $\mathrm{mm}$ - see text for details; sumFA = composite asymmetry score - see text for details). Results of Levene's test for heterogeneity of variances are also shown. $P=$ probability of no effect of temperature on the character value

\begin{tabular}{|c|c|c|c|c|c|c|c|c|c|c|}
\hline \multirow[t]{3}{*}{ Trait } & \multicolumn{5}{|c|}{ Females } & \multicolumn{5}{|c|}{ Males } \\
\hline & \multicolumn{3}{|c|}{ Temperature } & \multirow[b]{2}{*}{$F$} & \multirow[b]{2}{*}{$P$} & \multicolumn{3}{|c|}{ Temperature } & \multirow[b]{2}{*}{$F$} & \multirow[b]{2}{*}{$P$} \\
\hline & $25^{\circ} \mathrm{C}$ & $30^{\circ} \mathrm{C}$ & $37^{\circ} \mathrm{C}$ & & & $25^{\circ} \mathrm{C}$ & $30^{\circ} \mathrm{C}$ & $37^{\circ} \mathrm{C}$ & & \\
\hline WL & 0.0111 & 0.0098 & 0.0177 & 6.71 & 0.001 & 0.0087 & 0.0082 & 0.0110 & 1.65 & 0.194 \\
\hline D6 & 0.0092 & 0.0082 & 0.0119 & 2.33 & 0.099 & 0.0069 & 0.0070 & 0.0095 & 2.31 & 0.102 \\
\hline D8 & 0.0105 & 0.0082 & 0.0132 & 4.20 & 0.016 & 0.0081 & 0.0076 & 0.0090 & 0.59 & 0.553 \\
\hline sumFA & 0.0150 & 0.0046 & 0.0251 & 1.94 & 0.145 & 0.0048 & 0.0028 & 0.0036 & 2.70 & 0.106 \\
\hline
\end{tabular}

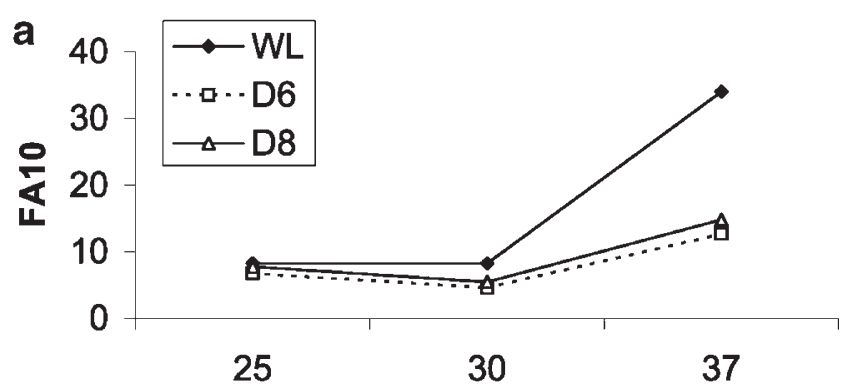

Temperature ${ }^{\circ} \mathrm{C}$

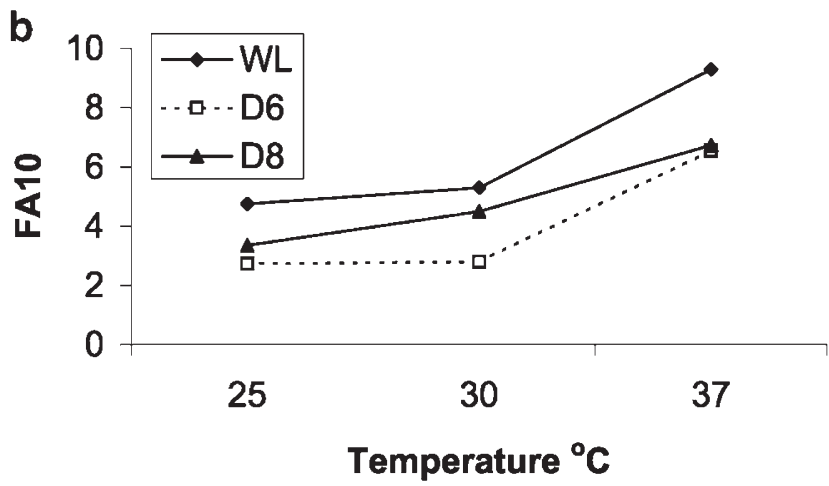

Figure 1 Relationship between FA10 values for a number of wing morphological traits and developmental temperature in (a) females and (b) males of a field population of Culex pipiens ( $\mathrm{WL}=$ wing length; D6 and D8 = measures of distance within the wing - see text for details).

developmental temperatures in either sex (Table 3). Heritability estimates of FA were low and frequently less than 0.1 (average 0.083, range 0.002-0.323) with the exception of $37^{\circ} \mathrm{C}$ for both sexes. Heritability estimates of wing size were all positive and greater than 0.1 in most cases (average 0.181 , range $0.043-0.33$ ) but none were significantly greater than zero.

\section{Discussion}

This study investigated the effect of genotype and temperature stress on certain wing and life history characters and wing FA in a field strain of the mosquito C. pipiens. Temperature had a significant effect on all of the life history and wing character values. There was also a signifi-
Table 3 Heritability $\left(h^{2}\right)$ ( \pm s.e.) estimates for trait size and fluctuating asymmetry of wing morphological characters in females and males of a field collected population of Culex pipiens mosquitoes reared under different temperatures. (WL, D6 and D8 measured in $\mathrm{mm}$; WA measured in $\mathrm{mm}^{2}$; for definition of these characters see text)

\begin{tabular}{|c|c|c|}
\hline & Female & Male \\
\hline & $h^{2} \pm$ s.e. & $h^{2} \pm$ s.e. \\
\hline \multicolumn{3}{|l|}{$25^{\circ} \mathrm{C}$} \\
\hline WL & $0.291 \pm 0.230$ & $0.147 \pm 0.153$ \\
\hline D6 & $0.161 \pm 0.182$ & $0.212 \pm 0.177$ \\
\hline D8 & $0.203 \pm 0.198$ & $0.209 \pm 0.175$ \\
\hline WA & $0.330 \pm 0.244$ & $0.210 \pm 0.183$ \\
\hline \multicolumn{3}{|l|}{ Wing trait FA } \\
\hline WL & $0.027 \pm 0.103$ & $0.055 \pm 0.223$ \\
\hline D6 & $0.088 \pm 0.136$ & $0.026 \pm 0.253$ \\
\hline D8 & $0.021 \pm 0.088$ & $0.144 \pm 0.208$ \\
\hline WA & $0.051 \pm 0.128$ & $0.024 \pm 0.226$ \\
\hline \multicolumn{3}{|l|}{$30^{\circ} \mathrm{C}$} \\
\hline \multicolumn{3}{|l|}{ Wing trait size } \\
\hline WL & $0.055 \pm 0.144$ & $0.250 \pm 0.216$ \\
\hline D6 & $0.070 \pm 0.175$ & $0.186 \pm 0.193$ \\
\hline D8 & $0.063 \pm 0.218$ & $0.177 \pm 0.186$ \\
\hline WA & $0.043 \pm 0.169$ & $0.186 \pm 0.194$ \\
\hline \multicolumn{3}{|l|}{ Wing trait FA } \\
\hline WL & $0.011 \pm 0.183$ & $0.008 \pm 0.157$ \\
\hline D6 & $0.029 \pm 0.125$ & $0.002 \pm 0.550$ \\
\hline D8 & $0.006 \pm 0.285$ & $0.016 \pm 0.112$ \\
\hline WA & $0.099 \pm 0.151$ & $0.022 \pm 0.135$ \\
\hline \multicolumn{3}{|l|}{$37^{\circ} \mathrm{C}$} \\
\hline \multicolumn{3}{|l|}{ Wing trait size } \\
\hline WL & $0.153 \pm 0.384$ & $0.105 \pm 0.295$ \\
\hline D6 & $0.285 \pm 0.378$ & $0.170 \pm 0.327$ \\
\hline D8 & $0.212 \pm 0.377$ & $0.185 \pm 0.319$ \\
\hline WA & $0.297 \pm 0.379$ & $0.144 \pm 0.277$ \\
\hline \multicolumn{3}{|l|}{ Wing trait FA } \\
\hline WL & $0.122 \pm 0.227$ & $0.068 \pm 0.418$ \\
\hline D6 & $0.007 \pm 0.223$ & $0.323 \pm 0.415$ \\
\hline D8 & $0.125 \pm 0.349$ & $0.222 \pm 0.312$ \\
\hline WA & $0.222 \pm 0.326$ & $0.271 \pm 0.427$ \\
\hline
\end{tabular}


cant genotype (family) effect on the values of the life history characters and two of the wing traits (D6 and D8). However, the heritability estimates for the wing traits were quite small, averaging 0.181 , and none of the individual estimates deviated significantly from zero. There is little consensus in the literature on the level of heritability of wing traits. Some authors, as with the present study, have found relatively small, non-significant heritability values (eg Woods et al, 1998; Leamy, 1999; Tomkins and Simmons, 1999; Bjorksten et al, 2000), whilst others have reported higher levels of wing trait heritability (see Bjorksten et al, 2000).

The levels of heritability found for wing trait FA were also low and, again, no heritability estimates were individually significantly different from zero. Even though these heritability estimates for FA are small they are likely to be exaggerated as a result of the full-sib design followed which could have inflated the estimates by including factors such as epistasis, maternal and dominance effects. These results contrast with the contentious claim by Møller and Thornhill (1997) that FA has a measurable heritable genetic basis. It has been argued that FA should have very low levels of genetic variation because the developmental process is genetically programmed to produce identical symmetrical phenotypes in bilaterally symmetrical organisms. It is only when the developmental process is overwhelmed by stress that deviation from the programmed trajectory occurs, leading to asymmetry. Consequently, heritability for FA should be zero or close to zero because any deviation from ideal symmetry is environmentally induced (Palmer, 1994).

However, it should be borne in mind that the population under study was derived from the field and placed under laboratory conditions. Genotype $\times$ environment interactions could have been quite large as a result of the transfer and could have interfered with the expression of heritable variation normally expressed under field conditions (Woods et al, 1998). On the other hand, it is well known that novel environmental conditions are likely to inflate levels of heritable genetic variation and hence estimates of heritability (Holloway et al, 1990). Drawing all of the evidence together: (1) the average FA heritability estimate was only 0.083, (2) a full-sib design was employed which yields a broad sense heritability estimate, and (3) the animals were reared under novel environmental conditions, hence it is likely that genetic variation for wing FA in C. pipiens is very small indeed.

It has been maintained by some authors (eg Møller, 1999) that FA is a condition-dependent asymmetry that increases under stressful conditions. However, this is not universally accepted and other studies have failed to reveal such a relationship (eg Fowler and Whitlock, 1994). In this study, wing FA was observed to increase with increase in temperature stress. However, female wing traits seem to be more responsive to temperature treatment than their male counterparts. In females, all the wing characters analysed were significantly larger at $37^{\circ} \mathrm{C}$ relative to $25^{\circ} \mathrm{C}$ and $30^{\circ} \mathrm{C}$, whereas in males only D6 changed significantly. Nevertheless, all other male wing characters showed an increase in FA with increase in temperature, albeit not significantly. Results of the present study contrast with previous studies using a laboratory strain of $C$. pipiens where increased temperature did not significantly increase wing trait FA (Mpho, 2000;
Mpho et al, 2000, 2001). The laboratory strain is maintained at reasonably high numbers but could have experienced periods of bottlenecks in the past, resulting in an elevated level of inbreeding. It is conceivable that inbreeding is a form of genetic stress which could raise levels of FA thus obliterating the effects of experimental treatments. Inbreeding is known to affect developmental stability in some experimental systems (Clarke et al, 1986; Deng, 1997; Eldridge et al, 1999; Roldan et al, 1998). A comparison of the FA of the two Culex strains revealed that the wing FA of the laboratory strain was consistently higher than that of the field strain at $25^{\circ} \mathrm{C}$ and $30^{\circ} \mathrm{C}$ in both sexes, which may support the assertion made above. The field strain is implicitly assumed to be an outbred strain. The high level of FA displayed by the laboratory strain may be close to the limit of viable load.

It has been proposed that FA may have value as an indicator of environmental stress induced by factors such as pollutants. If FA has a significant heritable component, then its use as a tool for biological monitoring of environmental stress would be limited because it would be difficult to distinguish between genetically determined FA and that which is induced by the environment. The results of this study indicate little heritable variation in FA of wing morphological traits in a field strain of $C$. pipiens and therefore suggest that FA may have value as an indicator of environmental condition, since FA is unlikely to be an indicator of genetic quality. However, FA should only be used as an indicator of environmental conditions with caution since there are many conflicting results in the literature and, if possible, should be complemented with other indicators, such as life history responses.

\section{Acknowledgements}

We are very grateful to Phil Wilson for technical help with the image analysis. M Mpho was supported by the University of Botswana. The image analysis equipment was purchased on NERC grant GR3/9463.

\section{References}

Allendorf FW, Leary RF (1986). Heterozygosity and fitness in natural populations of animals. In: Soulé ME (ed). Conservation Biology. The science of Scarcity and Diversity, Sinauer Assoc. Inc: Sunderland, MA. pp 57-76.

Bennett DM, Hoffmann AA (1998). Effects of size and fluctuating asymmetry on field fitness of the parasitoid Trichogramma carverae (Hymenoptera: Trichogrammatidae). J Anim Ecol 67: 580-591.

Bjorksten T, David P, Pomiankowski A, Fowler K (2000). Fluctuating asymmetry of sexual and nonsexual traits in stalk-eyed flies: a poor indicator of developmental stress and genetic quality. J Evol Biol 13: 89-97.

Clarke GM, Brand GW, Whitten MJ (1986). Fluctuating asymmetry: a technique for measuring developmental stress caused by inbreeding. Aust J Biol Sci 39: 145-153.

Cranston PP, Ramsdale CD, Snow KR, White GB (1987). Adults, Larvae and Pupae of British Mosquitoes (Culicidae). A Key. Freshwater Biological Association: Cumbria.

Deng HW (1997). Increase in developmental instability upon inbreeding in Daphnia. Heredity 78: 182-189.

Dobrin M, Corkum LD (1999). Can fluctuating asymmetry in adult burrowing mayflies (Hexagenia rigida, Ephemeroptera) be used as a measure of contaminant stress? J Great Lakes Res 25: 339-346. 
Eldridge MDB, King JM, Loupis AK, Spencer PBS, Taylor AC, Pope IC et al (1999). Unprecedented low levels of genetic variation and inbreeding depression in an island population of the black-footed rock-wallaby. Cons Biol 13: 531-541.

Falconer DS (1989). Introduction to Quantitative Genetics. 3rd edn. Longman: Harlow, Essex.

Floate KD, Fox AS (2000). Flies under stress: a test of fluctuating asymmetry as a biomonitor of environmental quality. Ecol Appl 10: 1541-1550.

Fowler K, Whitlock MC (1994). Fluctuating asymmetry does not increase with moderate inbreeding in Drosophila melanogaster. Heredity 73: 373-376.

Goulson D, Bristow L, Elderfield E, Brinklow K, Parryjones B, Chapman JW (1999). Size, symmetry, and sexual selection in the housefly, Musca domestica. Evolution 53: 527-534.

Holloway GJ, Povey SR, Sibly RM (1990). The effect of new environmental on adapted genetic architecture. Heredity 64: 323-330.

Hunt J, Simmons LW (1997). Patterns of fluctuating asymmetry in beetle horns: an experimental examination of the honest signalling hypothesis. Behav Ecol Sociobiol 41: 109-114.

Hunt J, Simmons LW (1998). Patterns of fluctuating asymmetry in beetle horns: no evidence for reliable signaling. Behav Ecol 9: $465-470$.

Leamy L (1997). Is developmental stability heritable? J Evol Biol 10: $21-29$.

Leamy L (1999). Heritability of directional and fluctuating asymmetry for mandibular characters in random-bred mice. J Evol Biol 12: 146-155.

Markow TA, Clarke GM (1997). Meta-analysis of the heritability of developmental stability: a giant step backward. J Evol Biol 10: 31-37.

Markow TA, Ricker JP (1992). Male size, developmental stability, and mating success in natural populations of three Drosophila species. Heredity 69: 122-127.

Meyer K (1997). Derivative free restricted estimation maximum likelihood DFREML: user notes.

Møller AP (1992). Parasites differentially increase fluctuating asymmetry in secondary sexual characteristics. J Evol Biol 5: 691-699.

Møller AP (1996). Sexual selection, viability selection, and developmental stability in the domestic fly Musca domestica. Evolution 50: 746-752.

Møller AP (1997). Developmental stability and fitness: a review. Am Nat 149: 916-932.

Møller AP (1999). Condition-dependent asymmetry is fluctuating asymmetry. J Evol Biol 12: 450-459.

Møller AP, Pomiankowski A (1994). Fluctuating asymmetry and sexual selection. In: Markow TA (ed). Developmental Instability, its Origins and Evolutionary Implications, Kluwer Academic Publishers: Dordrecht, The Netherlands. pp 269-281.

Møller AP, Thornhill R (1997). A meta-analysis of the heritability of developmental stability. J Evol Biol 10: 1-16.

Møller AP, Zamora-Munoz C (1997). Antennal asymmetry and sexual selection in a cerambycid beetle. Anim Behav 54: 1509-1515.
Mpho M (2000). Effects of environmental and genetic stress on life history and wing fluctuating asymmetry in mosquitoes. $\mathrm{PhD}$ thesis, The University of Reading.

Mpho M, Holloway GJ, Callaghan A (2000). The effect of larval density on life history and wing asymmetry in the mosquito Culex pipiens. Bull Entomol Res 90: 279-283.

Mpho M, Holloway GJ, Callaghan A (2001). A comparison of the effects of organophosphate insecticide exposure and temperature stress on fluctuating wing asymmetry and life history traits in Culex quinquefasciatus. Chemosphere 45: 713-720.

Palmer RA (1994). Fluctuating asymmetry analysis: A primer. In: Markow TA, (ed). Developmental Instability, its Origins and Evolutionary Implications. Kluwer Academic Publishers: Dordrecht, The Netherlands. pp 335-364.

Palmer RA, Strobeck C (1986). Fluctuating asymmetry: measurement, analysis, patterns. Ann Rev Ecol Syst 17: 391-421.

Rabitsch WB (1997). Levels of asymmetry in Formica pratensis Retz (Hymenoptera, Insecta) from a chronic metal-contaminated site. Environ Toxicol Chem 16: 1433-1440.

Roff DA (1997). Evolutionary Quantitative Genetics. Chapman and Hall: New York.

Roldan ERS, Cassinello J, Abaigar T, Gomendio M (1998). Inbreeding, fluctuating asymmetry, and ejaculate quality in an endangered ungulate. Proc Roy Soc Lond Series B 265: 243-248.

Sheridan L, Pomiankowski A (1997). Fluctuating asymmetry, spot asymmetry and inbreeding depression in the sexual coloration of male guppy fish. Heredity 79: 515-523.

Thornhill R, Sauer P (1992). Genetic sire effects on fighting ability of sons and daughters and mating success of sons in scorpionfly. Anim Behav 43: 225-264.

Tomkins JL, Simmons LW (1998). Female choice and manipulations of forceps size and symmetry in the earwig Forficula auricularia L. Anim Behav 56: 347-356.

Tomkins JL, Simmons LW (1999). Heritability of size but not symmetry in a sexually selected trait chosen by female earwigs. Heredity 82: 151-157.

Ueno H (1994). Fluctuating asymmetry in relation to two fitness components, adult longevity and male mating success in ladybird beetle, Harmonia axyridis (Coleoptera: Coccinellidae). Ecol Entomol 19: 87-88.

Van Dongen S, Sprengers E, Löfstedt C, Matthysen E (1999). Heritability of tibia fluctuating asymmetry and developmental instability in the winter moth (Operophetera brumata L.) (Lepidoptera, Geometridae). Heredity 82: 535-542.

Whitlock MC, Fowler K (1997). The instability of studies of instability. J Evol Biol 10: 63-67.

Windig JJ (1998). Evolutionary genetics of fluctuating asymmetry in the peacock butterfly (Inachis io). Heredity 80: 382392.

Woods RE, Hercus MJ, Hoffmann AA (1998). Estimating the heritability of fluctuating asymmetry in field Drosophila. Evolution 52: 816-824.

Zakharov VM (1992). Population phenogenetics: analysis of developmental stability in natural populations. Acta Zool Fennica 191: 7-30. 